\title{
Forging a New Alliance Between Succession and Restoration
}

\author{
Lawrence R. Walker, Joe Walker, and Roger del Moral
}

\section{Key Points}

1. Succession and restoration are intrinsically linked because succession comprises species and substrate change over time and restoration is the purposeful manipulation of that change.

2. During succession both orderly and unpredictable patterns emerge but some general rules offer theoretical and practical insights for restoration activities. These insights are not often utilized due to inadequate communication and a misconception that because restoration is focused on shorter temporal scales and is more goal-oriented, then concepts from succession may not apply.

3. Restoration potentially offers succession practical insights into how communities assemble, but a dearth of scientific protocols in the conduct of restoration has hindered this linkage.

\subsection{Introduction}

How does succession take place, after all, and what are the adaptive cycles, if any, and the feedback systems, assembly rules and other inherent functional, evolutionary or simply dynamic mechanisms that make ecosystems develop and interact in one way or another? If we can sort these questions out-biome by biome-then we will unquestionably be better placed to predict how much time, energy and capital of all sorts will be required, or should be allocated, to ecological restoration and rehabilitation. (Aronson and van Andel 2006)

Human impacts on our planet are increasing exponentially, endangering our lifestyles and our survival. By one estimate, we would need another whole planet to provide humans in developing countries with the resource base currently exploited by the developed nations (Wackernagel and Rees 1996). One positive approach to ameliorate ecological impacts such as habitat loss and environmental degradation involves the rapidly developing field of restoration ecology. Within the past few decades, practitioners have formed an initial body of theory, an international society, and several professional journals that are helping them to organize the many examples of successful and unsuccessful 


\section{Lawrence R. Walker et al.}

efforts to restore damaged ecosystems. Several recent books have explored the theoretical basis of restoration ecology (Walker and del Moral 2003, Temperton et al. 2004, van Andel and Aronson 2006) and have better defined where it sits in the integrated world of ecology.

Restoration ecology is a multidisciplinary approach that implements in a practical way concepts drawn from a wide range of disciplines, including conservation biology, disturbance ecology, ecological succession, ecohydrology, invasion biology, island biogeography, and landscape ecology (Zedler 2005, Young et al. 2005, van Diggelen 2006). In addition, restoration ecology incorporates many other ecological themes, for example, biodiversity, habitat heterogeneity, resilience, and sustainability. Restoration often addresses political, economic, and sociological issues as well. As a new subdiscipline of ecology, restoration ecology has been driven primarily by the urgency to repair damaged landscapes. However, the success of restoration ecology in the practical realm will depend on the strength of the ecological and process-based underpinnings. One key link is with ecological succession, a central concept in ecology since Warming (1895) and Cowles (1899 and 1901) recognized that species change was related to the time since stabilization on dunes. Succession theory now encompasses a large set of concepts useful for explaining the mechanisms of plant community and ecosystem development (Glenn-Lewin et al. 1992, Walker and del Moral 2003). Restoration is fundamentally the manipulation of succession and frequently focuses on acceleration of species and substrate change to a desired endpoint (Luken 1990). While successful restoration intentionally repairs the processes driving succession, most other studies of vegetation change (e.g., global climate change, invasion biology, consequences of regional and watershed degradation, and gap dynamics; Davis et al. 2005) focus on the unintended factors that disrupt succession (Fig. 1.1). Yet, restoration often proceeds with more reliance on engineering, horticulture, and agronomy than on ecology (Young et al. 2005). Is this because succession does not have the answers, because restoration does not need succession, or because of a lack of communication or irreconcilable differences between the two disciplines?

This book contends that the overlap between restoration and succession has yet to be adequately explored and that restoration and ecological succession can and should forge a stronger alliance than exists today. Restoration will develop more coherently if it better integrates ideas generated from a century of studies of ecological succession. Additionally, restoration has great but under-utilized potential to help elucidate the fundamental processes controlling ecological succession by monitoring how key system drivers respond to treatments. In this book, a range of restoration types will be identified that differ in spatial scales, ecological drivers, and restoration goals. Data will be presented from restoration activities around the world that come from habitats representing gradients of precipitation, temperature, soil age, and the stability, fertility, and toxicity of substrates. By exploring such contrasting environments, we will seek generalizations that link successional theory to the practice of restoration.

A central question of this book is: "What is the minimum amount of biophysical and successional information needed to restore a specific landscape or area?" In addition, we can ask: "What target values or indicators offer the means to evaluate the relative success or progress of particular restoration strategies?" 


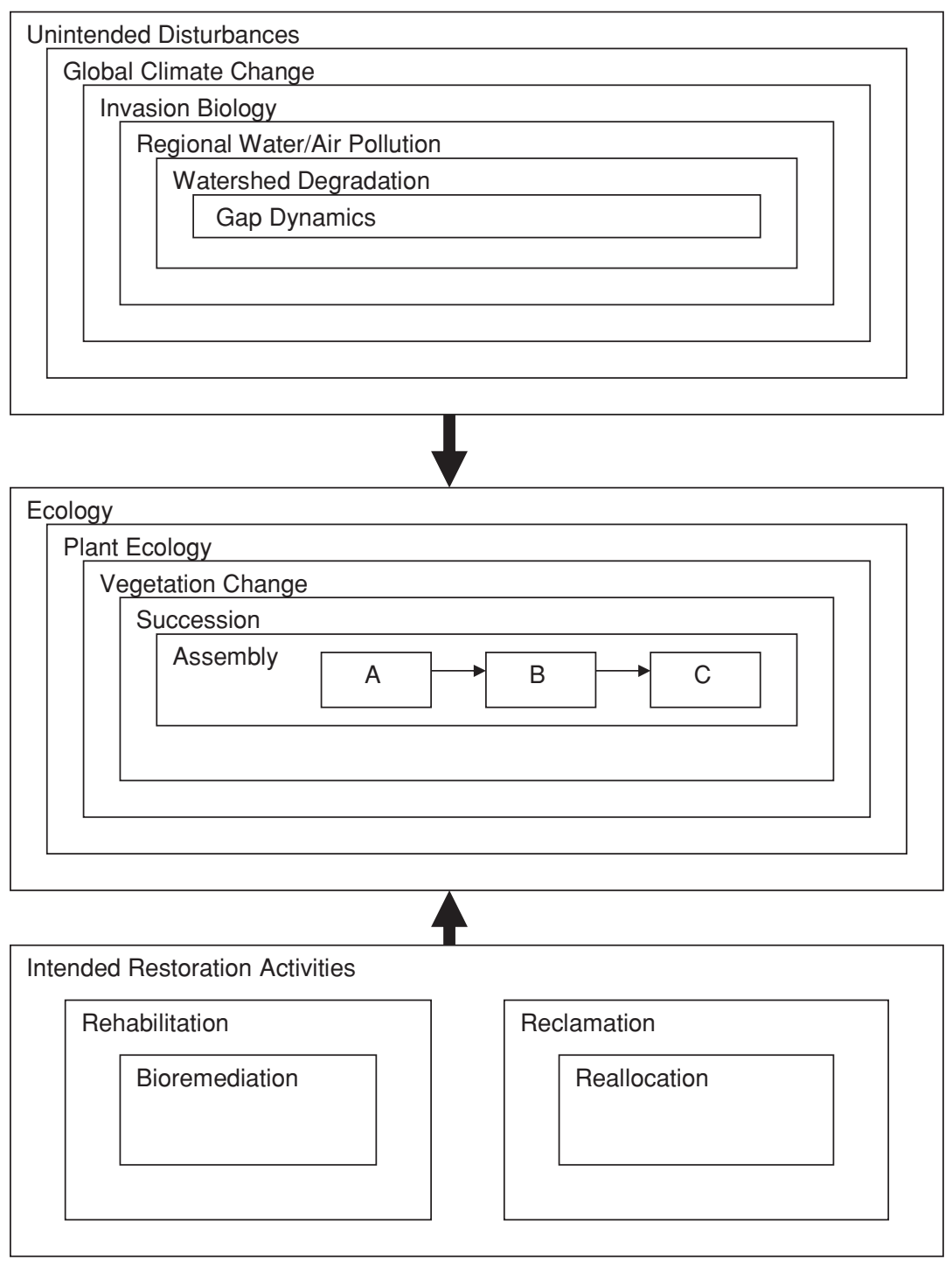

Figure 1.1 Plant succession (central box where community A proceeds to community $\mathrm{C}$ over time) can be impacted by unintended disruptions originating from disturbances that range in scale from global to local (top box) or by intended manipulations coming from restoration actions (bottom box). Restoration includes reclamation (any site amelioration), reallocation (alteration to a new function), rehabilitation (repair of ecosystem function), and bioremediation (reduction of site toxicity).

We will try to define what part of that information comes from successional theory and which key environmental drivers can be used to improve and measure restoration success. The urgency to repair damaged landscapes makes it critical to search for generalizations about the process of restoration. We suggest that examining restoration in the light of succession will aid in this search. Both of these topics are central to ecology-succession as the study of temporal dynamics and restoration as a critical application of ecological principles to an urgent societal need. 


\section{Lawrence R. Walker et al.}

Restoration usually addresses shorter time scales than successional studies, but is, nevertheless, dependent on the broader successional patterns of change for its success (Palmer et al. 1997). Practicing restoration outside the framework of succession may be likened to building bridges without attention to the laws of physics. Patterns of successional development can offer reference systems for the assessment of restoration actions and critical insights into the roles of species dispersal, species interactions, plant-soil interactions, and soil development. In turn, restoration offers a practical test of successional theories in developing a stable, restored system within the constraints of socioeconomic demands.

Both restoration and succession can focus on structure and composition (e.g., the vertical distribution and accumulation of biomass and species) or function (e.g., ecosystem processes such as the flow of energy or cycling of materials). However, while succession is generally confined to a given ecosystem, restoration may address broader spatial scales and encompass adjacent ecosystems, catchments, and landscapes.

When considering ways to restore a habitat, landscape, ecosystem, or watershed, we must address questions about why, where, how, what, and when. The reasons why we want to restore are largely influenced by societal values and the economic imperative for sustainable resources and services, and are addressed by social economics and governmental policies (Costanza et al. 1992). Where to restore may be self-evident, but in many cases, the targeted area (e.g., a waterlogged area) is merely a symptom of a broader problem (e.g., extensive tree clearing and increased recharge into the water table) that needs attention at a larger spatial scale. How to successfully restore an area depends largely on the level of understanding of the main drivers of the overall system, a clear definition of endpoints, the level of degradation (perhaps a new system state), available technologies, and economic constraints (Walker and Reuter 1996). What is restored is determined by existing conditions, social attitudes, political and economic demands, and by ecological constraints. Biodiversity, stability, and ecosystem function are linked to the particular restoration goals such as achieving a particular species composition, ensuring the duration of a certain community type, and the provision of necessary or desired ecosystem goods and services. Determining when to restore is complex and the decision can be constrained by competing demands for funding or perceived threats to plants, animals, and humans. From an ecological perspective, many sequential actions over a long time-period are more likely to yield desired results than a single action. Such incremental change over time defines ecological succession. Finally, the evaluation of what constitutes successful restoration is most informative when placed in the broader ecological context of expectations based on knowledge about succession.

In the next sections, we first define our perceptions about succession and restoration and give a brief overview of each discipline. Then we discuss how succession and restoration differ in scale, subject matter, and underlying paradigms. Next, we explore in more detail how succession and restoration are similar, what each discipline has to offer the other, and how they are both limited by a common set of abiotic and biotic constraints. Finally, we introduce a focal set of questions and provide a summary of each of the following chapters. 


\subsection{Concepts}

\subsubsection{Definitions}

Succession is the change in species composition and associated substrate changes over time. It is a dynamic process that is studied with descriptive, experimental, theoretical, and modeling approaches (McIntosh 1985). Formal, descriptive studies of succession began in the late 19th and early 20th centuries (Warming 1895, Cowles 1899 and 1901, Clements 1916), and were an extension of observations by natural historians, foresters, and agriculturalists during the previous several centuries (e.g., that ditches fill in with sediment and plant growth, that abandoned pastures gradually become forests, that stabilized dunes are colonized by plants). Experimental work began in the middle of the 20th century (Keever 1950) and continues to explore the mechanistic basis for species change [(reviewed as "neo-reductionism" in Walker and del Moral (2003)]. Theoretical studies of succession have had peaks of activity in the 1920s and 1930s (Ramensky 1924, Gleason 1926, Clements 1928), and again later in the century, emphasizing holism (Odum 1969), species life histories (Drury and Nisbet 1973, Huston and Smith 1987), reductionist models (Connell and Slatyer 1977, Pickett et al. 1987, Walker and Chapin 1987), and process-based computer models (Shugart and West 1980). Some current topics in succession include facilitation (Holmgren et al. 1997, Bruno et al. 2003, Walker et al. 2003), competition (Walker et al. 1989, Wilson 1999, Walker and del Moral 2003), herbivory (Davidson 1993, Fagan and Bishop 2000, Bishop et al. 2005), invasive species (Sheley and Krueger-Mangold 2003, Davis et al. 2005, Reinhart et al. 2005), priority effects (Samuels and Drake 1997, Corbin and D'Antonio 2004, Daehler and Goergen 2005), urban dynamics (Sukopp and Starfinger 1999, Robinson and Handel 2000, Sukopp 2004) and plantsoil interactions at both short-term (De Deyn et al. 2003, De Deyn et al. 2004, Bardgett et al. 2005) and long-term scales (Walker et al. 2001, Hedin et al. 2003, Wardle et al. 2004). Many of these topics are shared by other subdisciplines within ecology but succession is specifically concerned with their influence on temporal dynamics. There is some agreement on the basic principles that drive succession but still no overarching paradigm for the myriad possible outcomes of succession (McIntosh 1999, Walker and del Moral 2003).

Restoration, in a broad sense, is the manipulation of a disturbed habitat or landscape to a desired condition. It is therefore more focused on specific outcomes than studies of succession, which attempt to understand the nature of vegetation change. Restoration has been part of agricultural and forestry activities and other human impacts on ecosystems for a long time, as with shifting agriculture or efforts to replenish eroded soils. Restoration ecology attempts to bring some ecological principles into restoration actions and focuses almost entirely on habitats impacted by or relevant to human activities. Restoration ecology is a more practical management science than the study of succession and is more integrated with socioeconomic and political realities. Restoration ecology is also a younger scientific discipline than succession, with conceptual origins in the 1940s (e.g., Leopold 1949), but formalization as a field of study only in the 1980s (Bradshaw and Chadwick 1980, Cairns 1980, Jordan et al. 1987). While still largely descriptive, each restoration action is, in practice, 


\section{Lawrence R. Walker et al.}

an experiment. Integration of experimentation and restoration activities with the intent to seek generalization is increasingly common (Dobson et al. 1997, Gilbert and Anderson 1998, Zedler and Callaway 2003). Formal development of the theoretical basis of restoration ecology is, however, still in its early stages (Cairns and Heckman 1996, Hobbs and Norton 1996, Young et al. 2005).

In this book, we will use very broad definitions of succession and restoration. In this way, succession encompasses severely damaged or new substrates (primary) and more intact ones (secondary). Succession also addresses many possible trajectories (e.g., retrogressive, direct regeneration, divergent, convergent) and types of organismal change (e.g., of animals, plants, or microbes). We are also not limited by the disturbance type that initiates succession, although the bias will be toward disturbances of most relevance to humans and restoration efforts. Restoration will be used in the broadest sense as well (Fig. 1.1; Aronson et al. 1993), incorporating reclamation (any site amelioration), reallocation (alteration to a new function), rehabilitation (repair of ecosystem function), and bioremediation (reduction of site toxicity). Our use of restoration sensu lato does not encompass the full recovery of an ecosystem to its pre-disturbance structure and function (restoration sensu stricto), as we regard that goal as generally unrealistic.

\subsubsection{Differences}

Succession and restoration differ in scale, subject matter, and underlying paradigms. Succession most commonly addresses time intervals between 10 and 200 years, encompassing the life times of most perennial vascular plants. Restoration typically focuses on periods between 1 and 20 years, or the duration of human involvement in most projects. Both can, of course, address a wider range of temporal scales, particularly successional trajectories that can extend to thousands of years (Walker et al. 1981, Crews et al. 1995, Wardle et al. 2004). The use of chronosequences, or space for time substitutions (Pickett 1989), is essential for longer time scales and is well established in successional studies but is not commonly used for restoration planning (Walker et al. 2001, Hobbs 2005). Spatial scales can differ also, with succession often focusing at smaller scales.

The subjects that the field of succession most often addresses are tightly linked to either specific disturbances (often natural ones) or the disturbance regime (the composite of all disturbances in a region). The link to humans is not a prerequisite, although more successional studies address changes following agriculture or logging (Glenn-Lewin et al. 1992) than natural processes such as glacial melt or volcanic eruptions (Walker and del Moral 2003). In contrast, most studies of restoration tackle only those disturbances most relevant to humans. Succession focuses on changes within one successional sequence (sere), and remains within one ecosystem. Restoration, on the other hand, often addresses adjoining ecosystems, such as those within a watershed, urban area, or landscape (Holl et al. 2003). In this way, restoration can encompass multiple seres such as those that follow from agriculture and logging within the same landscape (van Diggelen 2006).

It is evident throughout this account that many of the basic paradigms of succession and restoration differ substantially. Succession, with its roots in natural history and observations about habitat changes over time, has developed a 
conceptual framework entrenched in scientific methodology and motivated to understand mechanisms of species change. This is a classic supply paradigm, with a proliferation of information that may someday be useful. Restoration has developed closer links to the practical concerns of managers and is more action-oriented with motivation to achieve particular results. This is a classic demand paradigm, with the practical issues of day-to-day management demanding sustainable practices based on environmental knowledge. Restoration ecology has begun to develop a stronger conceptual framework but the application of successional studies to practical management issues is still inadequate.

\subsubsection{Similarities and Linkages}

Despite the different origins and approaches noted above, succession and restoration share many traits that make stronger linkages an achievable proposition (Table 1.1). Both are concerned with responses to disturbance (especially human-initiated ones). They both deal with a subset of the landscape and are dependent on knowledge about ecosystem function, community structure and dynamics, and species attributes in order proceed. In addition, both are concerned with the modeling and prediction of the sequence of discrete events called successional trajectories. We next explore these linkages in terms of what each discipline offers the other.

\subsubsection{Succession to Restoration}

Because of a century of study in many areas of the globe, the discipline of succession can offer substantial contributions to the discipline of restoration. Succession offers both a long-term perspective and short-term predictions on species dynamics and provides a reference system for restoration that can suggest likely outcomes following management actions (Aronson and van Andel 2006). Methods developed within or used in studies of succession that are or can be incorporated into restoration include, for example, functional plant groups (vital attributes), species filters, ecosystem assembly, state and transition models, fuzzy set theory, Markov processes, and biogeochemical modeling.

Table 1.1 Topics that link succession and restoration. Studies of succession and restoration share much overlap in subject matter. Succession offers restoration insights into: responses to different disturbance regimes; how responses to various ecosystem functions reflect changes in community structure and dynamics as measured by species attributes; generalizations about possible trajectories; and models that predict possible outcomes of succession. Restoration offers succession practical data on amelioration of infertility and other abiotic constraints as well as input about species interactions in particular circumstances and the sustainability of various successional communities.

\begin{tabular}{ll}
\hline Topic & Shared Information \\
\hline Disturbance & Loss of biological legacy (severity), disturbance regime \\
Ecosystem Function & $\begin{array}{c}\text { Energy flow, carbon accumulation and storage, nutrient dynamics, soil properties, } \\
\text { water cycle }\end{array}$ \\
$\begin{array}{l}\text { Community Structure and } \\
\text { Composition }\end{array}$ & $\begin{array}{c}\text { Biomass, vertical distribution of leaf area, leaf area index, species richness, species } \\
\text { evenness, species density, spatial aggregation }\end{array}$ \\
$\begin{array}{l}\text { Community Dynamics } \\
\text { Species Attributes }\end{array}$ & $\begin{array}{l}\text { Facilitation, inhibition, dispersal (priority effects and entrapment), sustainability } \\
\text { Life history characteristics (pollination syndrome, germination, establishment, } \\
\text { grajectories }\end{array}$ \\
Models & Rates and tongevity) \\
\hline
\end{tabular}




\section{Lawrence R. Walker et al.}

Succession contributes to an understanding that multiple trajectories are possible so restoration goals must remain flexible and open to change. Succession theory also suggests that reconstruction of dynamic ecosystems must incorporate responses to changes from within the system (typically from species interactions) and from disturbances from outside (typically from modifications to abiotic variables but also from biotic invasions). These kinds of changes, some predictable, others less so, mean that restoration must follow an adaptive management style (Zedler and Callaway 2003). Insights from succession can elucidate various ecosystem functions for restoration, including local hydrology, soil development, energy flow, nutrient dynamics, and carbon accumulation and storage (Table 1.1). At the plant community level, structural insights from succession include information on biomass, leaf area distribution, leaf area indices, species richness, species evenness, species density, and spatial aggregation that can help restoration ecologists. Community dynamics, a common topic for successional studies, helps explain the type (plant/soil, plant/plant, and plant/animal) and mode (facilitation, competitive inhibition) of species interactions as well as insights into dispersal (priority effects, entrapment). Successional studies also offer information about various life history characteristics (pollination, germination, establishment, growth, longevity) of key species as well as many other plant traits. Modeling species change can help generalize lessons about restoration from site-specific studies to reach more broadly applicable conclusions. Many of these concepts can help the people working on restoration projects to organize data collection, determine immediate restoration activities, estimate rates of change, and plan the long-term search for appropriate development of generalizations and understanding of mechanisms.

\subsubsection{Restoration to Succession}

Restoration studies potentially can provide a wealth of information to improve our understanding of succession. Practical tests of successional theory are obvious outcomes if the restoration activities use normal scientific protocols such as inclusion of a control, quantitative data collection, planned treatment comparisons, statistical analysis, and peer-reviewed publication of results. Restoration can also provide insights into both historical and biological links among landscape components as well as potential details on impacts to the water cycle or on substrate changes. Efforts to address soil toxicity and infertility, as well as efforts to promote propagule dispersal to the site, are activities that can contribute to understanding the physiology and life histories of key species. Restoration activities can also help inform us about community structure (species richness, evenness, density, spatial aggregation) and community sustainability. Species performance in restoration offers insights into life history characteristics, perhaps generating more information than strictly successional studies. Finally, restoration has much to teach succession by asking practical questions about trajectories and targets. For example, can certain successional stages be skipped in order to jump-start succession or hasten the establishment of a desired community?

\subsection{Common Constraints}

Succession and restoration are limited by a similar set of abiotic and biotic constraints that include plant dispersal, germination, and growth, as well as species 
turnover and ecosystem resilience. Overcoming these constraints is a major part of the task of any successful restoration. Successional studies can explain how such constraints are naturally overcome, both for short-term restoration tactics to establish vegetative cover and for long-term efforts to restore ecosystem resilience relative to the prevailing disturbance regime (Walker and del Moral 2003). Although site-specific solutions are the most dependable resolution to each set of interacting constraints, we offer a few generalizations below and some examples that illustrate how succession can assist restoration efforts in overcoming the constraints. Later chapters will expand on many of these topics.

\subsubsection{Abiotic Factors and Their Amelioration}

Generalizations about colonization, plant growth, and succession are highly dependent on climate and the nutritional and physical properties of the substrate. Vascular plant establishment and growth are frequently restricted by water availability (Cody 2000). Restoration in dry, cold conditions often involves addition of mulches to conserve water and promote mineralization such as on gold mine spoils in central Alaska (Densmore 1994). Restoration in dry, hot conditions can sometimes be improved by decompaction of soils to increase permeability, as on a chronosequence of abandoned roads in the Mojave Desert (Bolling and Walker 2000). Poor establishment and slow growth under either temperature extreme can be aided by microclimate amelioration using other vegetation as nurse plants to provide shade or windbreaks and surface contouring. However, the positive effect of a vegetative cover decreases as the environment becomes more favorable (Callaway and Walker 1997, Holmgren et al. 1997). Therefore, solutions appropriate to early stages of succession may not work in later, more fertile stages.

Substrate quality, measured by age, stability, fertility, and toxicity, can affect restoration success. Very old soils are often low in phosphorus (Walker and Syers 1976, Crews et al. 1995, Wardle et al. 2004). Poor nutritional status due to weathering and leaching (Gunn and Richardson 1979), structural decline, crusting, and the acidification of the topsoil are also characteristics of old soils (Russell and Isbell 1986). Restoration on older soils, such as are found in many parts of Australia, can be a very difficult proposition because of the long-term accumulation of salt from atmospheric accession and its subsequent mobilization (Williams et al. 2001).

Substrate stability depends on slope, rainfall amount and intensity, soil texture and erodability, vegetative cover, and grazing type, frequency, and intensity. Recurring disturbances will also impact stability and therefore restoration efforts. On landslides in Puerto Rico, restoration efforts include a variety of physical and biotic interventions from mulches to planting to recontouring the whole hillside, each adjusted to the disturbance regime of a particular landslide. Despite all these restoration efforts, the dense growth of native vine-like ferns that invade via clonal growth from the edges appear to be the best stabilizers (Walker 2005). The drawback with the ferns is that they can delay succession for several decades (Walker et al. 1996). Dunes provide another example of recurring disturbances where stabilization is critical before succession can proceed. Reduction of human impacts, planting rather than sowing grasses or fast-growing trees, and artificial stabilization are all possible methods of accelerating dune succession (Nordstrom et al. 2000).

\author{
Au: The \\ meaning of \\ the sentence \\ is not clear. It \\ seems some \\ word is \\ missing after \\ "such as...." \\ Please check $_{\lambda}$
}


10 Lawrence R. Walker et al.

Grazing is a major cause of soil erosion in such places as Iceland and China. In Iceland, 1000 years of heavy grazing have left little protection from wind, rain, and ice heaving. Native ground cover and fences to exclude grazers allow Betula forests to develop within 50 years (Aradottir and Eysteinsson 2004) but pressure from sheep farmers for open grazing land, especially in the vulnerable uplands, keeps most of Iceland deforested. The Loess Plateau in central China has experienced even longer agricultural activities than Iceland ( $>2000$ years). Cultivation and the highly erodable, aeolian soils have led to severe erosion problems and huge sediment loads in the Yellow River (McVicar et al. 2002). The most actively eroded areas are being replaced with perennial vegetation. Some $150,000 \mathrm{~km}^{2}$ of eroded land has been controlled by the various conservation measures (Rui et al. 2002).

Substrate fertility is a very common constraint for restoration, especially where little or no topsoil remains. Loss of organic soil reduces nitrogen levels critical for revegetation (Classen and Hogan 2002). Organic layers can be eroded or leached where rainfall is sufficient such as on Himalayan landslides (Pandey and Singh 1985) or hardpans may develop at the surface where evaporation exceeds precipitation in arid lands (Zougmore et al. 2003). To restore such soils, a balance is needed between sufficient fertilization that promotes succession and excessive fertilization that favors strong competitors that reduce biological diversity and inhibit further succession (Prach 1994, Marquez and Allen 1996, Walker and del Moral 2003). For example, fertilization of nonnative grasses delayed recolonization of native tundra species on the Alaskan pipeline corridor by several decades (Densmore 1992). In such cases, restoration goals were limited to simply providing vegetative cover and failed to address species interactions and successional dynamics.

Another common constraint is toxic surfaces such as found on landfills and mine tailings. Under such conditions, restoration goals are usually relaxed and any cover is considered a success. Approaches include sealing the surface, topsoil and mycorrhizal additions, conversion to wetlands, sowing with grasses that are tolerant of the toxins, and planting trees (Bradshaw 1952, Wali 1992, Cooke 1999). Bioremediation, or the direct amelioration of toxic conditions with plants and microbes, is a growing field, but one that has not yet been incorporated into succession ${ }_{\lambda}$ frameworks (Walker and del Moral 2003).

\subsubsection{Establishment}

The first stage of succession involves successful dispersal of plant reproductive units to the site of interest, while restoration involves deliberate sowing of those same plants or appropriate plant introductions, but usually after some site preparation. Preliminary assessment of the viability and quantity of natural seed rain can determine if introductions are needed. Where dispersal is determined to be a limiting factor, perches can encourage introduction of relatively heavy, bird-dispersed seeds, as on landslides in Puerto Rico (Shiels and Walker 2003). In other cases, assessment of pollination and seed production at the site or in the vicinity will also be required. For example, restoration of the perennial rosette Argyroxiphium sandwicense in Hawaii was improved by studies that determined that it was pollinator limited and largely self-incompatible (Powell 1992). These discoveries led to artificial pollination to increase seed set and clustered out-plantings to improve cross-pollination. Existing seed banks are 
another variable to evaluate, as they do not always reflect the existing or predisturbance vegetation. For example, in native Hawaiian forests most of the seed bank is composed of alien plants (Drake 1998). If no viable seeds exist in the soil or there is no seed rain, desirable species can be sown or transplanted to accelerate both restoration and succession (Pärtel et al. 1998). Germination and early survival are the final steps to establish initial populations. Germination requirements vary enormously among plants with the most known about species of agricultural interest. Conditions for seedling survival are more generic: protection from herbivory and adequate warmth, nutrients, and water. Vegetative reproduction can aid restoration, especially in primary succession, and bypass many of the constraints noted above (del Moral and Jones 2002). Successional contributions, aside from direct experience with particular species, will largely be to provide an overall demographic context for restoration efforts.

\subsubsection{Growth and Species Interactions}

Once plants have survived their first growing season at a site, new factors become the focus of both succession and restoration. Adequate growth will be assessed according to the goals of the restoration project. In most cases, rapid growth is desired. Belowground growth helps promote substrate stabilization and deters desiccation of seedlings while rapid growth aboveground can help reduce surface erosion and deter losses from ground-dwelling herbivores. Successional studies help identify bottlenecks to successful growth and potential effects of species interactions. Many studies of succession have focused on the relative balance between competition and facilitation and have direct relevance to restoration. One general lesson suggests that facilitation will be more important for species change (and restoration) in severe habitats while competition dominates more fertile, mesic, and stable habitats (Callaway and Walker 1997). However, many species interactions embody the whole suite of competitive to facilitative effects on each other (Bronstein 1994) and the relative balance of these can shift during the life span of each species (Bruno 2000, Walker et al. 2003), particularly as relative growth rates or sizes change (Callaway and Walker 1997). For example, the shrub Mimosa luisana initially facilitates establishment of the cactus Neobuxbaumia tetetzo but eventually the cactus inhibits the shrub's growth and reproduction (Flores-Martinez et al. 1994). In contrast, Alnus sinuata shrubs in Alaska initially inhibited germination of Picea sitchensis trees but the nitrogen added by A. sinuata facilitated later growth of P. sitchensis (Chapin et al. 1994). Species interactions, whether facilitative or inhibitory, are often site- and species-specific. Nevertheless, restoration activities can improve recruitment and survival rates when they incorporate the latest relevant information about species interactions.

\subsubsection{Ecosystem Resilience}

The ultimate goal of a restoration project is to have a self-sustaining community that includes natural species turnover and resilient responses to the local disturbance regime (Table 1.1). Both succession (Glenn-Lewin et al. 1992, Walker and del Moral 2003) and restoration (Temperton et al. 2004, van Andel and Aronson 2006) are moving away from the notion of a static climax community toward a more dynamic view of communities. In this dominant view, communities actively change in response to such internal processes as species change 


\section{Lawrence R. Walker et al.}

(driven largely by species longevity, competition, facilitation, or invasions) and external drivers including historical climate change (McGlone 1996) and disturbances that alter structure by damaging or removing biomass. Few restoration projects have recreated such ideal conditions. Indeed, those that come closest are probably those with the least human intervention. Nonetheless, many principles gleaned from studies of succession can provide a good foundation for restoration programs, including the restoration of novel ecosystems dominated by new combinations of native and nonnative species (Aronson and van Andel 2006) and the possibility of developing natural ecosystem mimicry in agricultural landscapes (Leroy et al. 1999).

\subsection{Book Outline}

Each chapter in this book will focus on a set of central questions in order to develop both new theoretical advances in the field of ecosystem restoration and practical tools to improve ecosystem management. These questions are:

1. What site and landscape factors are likely to determine and/or limit restoration?

2. What do observations from the study of succession offer for improved restoration practice?

3. How can restoration practices be improved across many sites and landscapes with the application of these successional concepts?

4. How can restoration practices inform our understanding of succession?

By addressing these questions for a wide variety of ecosystems we hope to accomplish the following goals:

1. Provide the latest understanding of linkages between successional theory and restoration practice.

2. Increase potential restoration effectiveness by providing instructive models from natural recovery processes.

3. Consider applications from local to landscape scales.

4. For the first time, consider landscape ages as key drivers linking succession and restoration.

5. Link the emphasis on general plant traits and results (e.g., ecosystem function) to succession and restoration.

6. Examine restoration and management of ecohydrological issues and how they are linked to succession.

7. Integrate the crucial role of soil biota as a means to manipulate trajectories with other aspects of system manipulation.

Chapter 2 (R. del Moral, L. Walker, J. Bakker) examines the lessons and insights gained from practical experiences in succession that can improve restoration results. The focus is on processes such as dispersal, germination, competition, and herbivory that can be easily manipulated and the bottlenecks that must be overcome in order to restore an optimal balance between ecosystem structure and function.

Chapter 3 (D. Wardle, D. Peltzer) examines the restoration of soil ecosystems within the context of fertility and soil biota. This chapter addresses the role of sequential changes that occur during the development of soils following 
disturbance and how to best manipulate and use soil biota as engineers of restoration success.

Chapter 4 (J. Walker, P. Reddell) asserts that succession and hence restoration endpoints on old landscapes differ from succession and restoration actions on young landscapes. This chapter highlights retrogressive succession and addresses how temporal and spatial scales impact the linkages between succession and practical restoration efforts. Old landscapes are contrasted with more recent surfaces to bridge many temporal scales. A tropical forest in northern Australia and salinized landscapes in semiarid Australia are used as examples.

Chapter 5 (J. Schrautzer, A. Rinker, K. Jensen, F. Müller, P. Schwartze, K. Dierßen) addresses the utility of broad ecosystem-based management and the contributions of successional concepts and catchment scale dynamics to restoration of European fens. Modeled values for key ecosystem variables are used to contrast retrogressive succession following increased disturbance intensity and progressive succession following abandonment of former fens.

Chapter 6 (K. Prach, R. Marrs, P. Pyšek, R. van Diggelen) explores the degree to which we can manipulate succession. When is it best to let succession proceed without intervention? When is it best to arrest succession? What must be done to integrate the reality of invasive species into restoration plans?

Chapter 7 (R. Hobbs, A. Jentsch, V. Temperton) explores the linkages between restoration and succession using the concepts of species assembly disturbance. Do assembly rules and self-organizational principles help restoration planning and increase restoration effectiveness?

Chapter 8 (R. Hobbs, L. Walker, J. Walker) integrates the concepts covered in this book, attempts to answer our core set of questions, and explores how succession can assist restoration planning, our understanding of species trajectories, and temporal changes in ecosystem functions.

Acknowledgments: Comments by Peter Bellingham, Viki Cramer, Karel Prach, Vicky Temperton, and Sue Yates greatly improved this chapter. Lawrence Walker acknowledges sabbatical support from the University of Nevada Las Vegas and Landcare Research, New Zealand.

\section{References}

Aradottir, A. L., and Eysteinsson, T. 2004. Restoration of birch woodlands in Iceland. In: Restoration of Boreal and Temperate Forests. J. Stanturf and P. Madsen (eds.). Boca Raton: CRC/Lewis, pp. 195-209.

Aronson, J., and van Andel, J. 2006. Challenges for ecological theory. In: Restoration Ecology. J. van Andel and J. Aronson (eds.). Oxford, U.K.: Blackwell, pp. 223-233.

Aronson, J., Floret, C., LeFloc'h, E, Ovalle, C., and Pontanier, R. 1993. Restoration and rehabilitation of degraded ecosystems in arid and semiarid regions. I. A view from the South. Restoration Ecology 1:8-17.

Bardgett, R. D., Bowman, W. D., Kaufman, R., and Schmidt, S. K. 2005. A temporal approach to linking aboveground and belowground ecology. Trends in Ecology and Evolution 20:634-641.

Bishop, J. G., Fagan, W. F., Schade, J. D., and Crisafulli, C. M. 2005. Causes and consequences of herbivory on prairie lupine (Lupinus lepidus) in early primary succession. In: Ecological Responses to the 1980 Eruption of Mount St. Helens. V. H. Dale, F. J. Swanson, and C. M. Crisafulli (eds.). New York: Springer, pp. 151-161. 


\section{Lawrence R. Walker et al.}

Bolling, J. D., and Walker, L. R. 2000. Plant and soil recovery along a series of abandoned desert roads. Journal of Arid Environments 46:1-24.

Bradshaw, A. D. 1952. Populations of Agrostis tenuis resistant to lead and zinc poisoning. Nature 169:1098.

Bradshaw, A. D., and Chadwick, M. J. 1980. The Restoration of Land: The Ecology and Reclamation of Derelict and Degraded Land. Oxford, U.K.: Blackwell.

Bronstein, J. L. 1994. Conditional outcomes in mutualistic interactions. Trends in Ecology and Evolution 9:214-217.

Bruno, J. F. 2000. Facilitation of cobble beach plant communities through habitat modification by Spartina alterniflora. Ecology 81:1179-1192.

Bruno, J. F., Stachowicz, J. J., and Bertness, M. D. 2003. Inclusion of facilitation into ecological theory. Trends in Ecology and Evolution 18:119-125.

Cairns, J. (ed.). 1980. The Recovery Process in Damaged Ecosystems. Ann Arbor, MI: Ann Arbor Science Publishers.

Cairns, J., and Heckman, J. R. 1996. Restoration ecology: The state of an emerging field. Annual Review of Energy and Environment 21:167-189.

Callaway, R. M., and Walker, L. R. 1997. Competition and facilitation: A synthetic approach to interactions in plant communities. Ecology 78:1958-1965.

Chapin, F. S., III., Walker, L. R., Fastie, C. L., and Sharman, L. C. 1994. Mechanisms of primary succession following deglaciation at Glacier Bay, Alaska. Ecological Monographs 64:149-175.

Claasen, V. P., and Hogan, M. P. 2002. Soil nitrogen pools associated with revegetation of disturbed sites in the Lake Tahoe area. Restoration Ecology 10:195-203.

Clements, F. E. 1916. Plant Succession: An Analysis of the Development of Vegetation. Washington, D.C.: Carnegie Institution of Washington Publication, 242 pp.

Clements, F. E. 1928. Plant Succession and Indicators. New York: H.W. Wilson.

Cody, M. 2000. Slow-motion population dynamics in Mojave Desert perennial plants. Journal of Vegetation Science 11:351-358.

Connell, J. H., and Slatyer, R. O. 1977. Mechanisms of succession in natural communities and their roles in community stability and organization. The American Naturalist 111:1119-1144.

Cooke, J. A. 1999. Mining. In: Ecosystems of Disturbed Ground. L. Walker (ed.). Amsterdam, The Netherlands: Elsevier, pp. 365-384.

Corbin, J. D., and D'Antonio, C. M. 2004. Competition between native perennial and exotic annual grasses: Implications for an historical invasion. Ecology 85:12731283.

Costanza, R., Norton, B. G., and Haskell, B. D. 1992. Ecosystem Health: New Goals for Environmental Management. Washington, D.C.: Island Press.

Cowles, H. C. 1899. The ecological relations of the vegetation on the sand dunes of Lake Michigan. 1. Geographical relations of the dune flora. Botanical Gazette 27:95-117, 167-202, 281-308, 361-391.

Cowles, H. C. 1901. The physiographic ecology of Chicago and vicinity: A study of the origin, development, and classification of plant societies. Botanical Gazette 31:73108, 145-182.

Crews, T., Kitayama, K, Fownes, J., Riley, R. Herbert, D., Mueller-Dombois, D., and Vitousek, P. 1995. Changes in soil phosphorus fractions and ecosystem dynamics across a long chronosequence in Hawaii. Ecology 76:1407-1424.

Daehler, C. C., and Goergen, E. M. 2005. Experimental restoration of an indigenous Hawaiian grassland after invasion by Buffel grass (Cenchrus ciliaris). Restoration Ecology 13:380-389.

Davidson, D. W. 1993. The effects of herbivory and granivory on terrestrial plant succession. Oikos 68:23-35.

Davis, M. A., Pergl, J., Truscott, A.-M., Kollmann, J., Bakker, J. P., Domenech, R., Prach, K., Prieur-Richard, A.-H., Veeneklaas, R. M., Pyšek, P., del Moral, R., Hobbs, 
R. J., Collins, S. L., Pickett, S. T. A., and Reich, P. B. 2005. Vegetation change: A reunifying concept in plant ecology. Perspectives in Plant Ecology, Evolution and Systematics 7:69-76.

De Deyn, G. B., Raaijmakers, C. E., and Van der Putten, W. H. 2004. Plant community development is affected by nutrients and soil biota. Journal of Ecology 92:824-834.

De Deyn, G. B., Raaijmakers, C. E., Zoomer, H. R., Ber, M. P., de Ruiter, P. C., Verhoef, H. A., Bezemer, T. M., and van der Putten, W. H. 2003. Soil invertebrate fauna enhances grassland succession and diversity. Nature 422:711-713.

del Moral, R., and Jones, C. C. 2002. Early spatial development of vegetation on pumice at Mount St. Helens. Plant Ecology 161:9-22.

Densmore, R. V. 1992. Succession on an Alaskan tundra disturbance with and without assisted revegetation with grass. Arctic and Alpine Research 24:238-243.

Densmore, R. V. 1994. Succession on regarded placer mine spoil in Alaska, USA, in relation to initial site characteristics. Arctic and Alpine Research 26:354-363.

Dobson, A. P., Bradshaw, A. D., and Baker, A. J. M. 1997. Hopes for the future: Restoration ecology and conservation biology. Science 277:515-522.

Drake, D. R. 1998. Relationships among the seed rain, seed bank and vegetation of a Hawaiian forest. Journal of Vegetation Science 9:103-112.

Drury, W. H., and Nisbet, I. C. T. 1973. Succession. Journal of the Arnold Arboretum 54:1147-1164.

Fagan, W. F., and Bishop, J. G. 2000. Trophic interactions during primary succession: Herbivores slow a plant reinvasion at Mount St. Helens. The American Naturalist 155:238-251.

Flores-Martinez, A., Ezcurra, E., and Sanchez-Colon, S. 1994. Effect of Neobuxbaumia tetetzo on growth and fecundity of its nurse plant Mimosa luisana. Journal of Ecology $82: 325-330$

Gilbert, O. L., and Anderson, P. 1998. Habitat Creation and Repair. Oxford: Oxford University Press.

Gleason, H. A. 1926. The individualistic concept of the plant association. Bulletin of the Torrey Botanical Club 53:7-26.

Glenn-Lewin, D. C., Peet, R. K., and Veblen, T. T. $\wedge$ 1992. Plant Succession: Theory and Prediction. London: Chapman and Hall.

Gunn, R. H., and Richardson, P. D. 1979. The nature and possible origins of soluble salts in deeply weathered landscapes in eastern Australia. Australian Journal of Soil Research 17: 197-215.

Hedin, L. O., Vitousek, P. M., and Matson, P. A. 2003. Nutrient losses over four million years of tropical forest development. Ecology 84:2231-2255.

Hobbs, R. J. 2005. The future of restoration ecology: Challenges and opportunities. Restoration Ecology 13:239-224

Hobbs, R. J., and Norton, D. A. 1996. Towards a conceptual framework for restoration ecology. Restoration Ecology 4:93-110.

Holl, K. D., Crone, E. E., and Schultz, C. B. 2003. Landscape restoration: Moving from generalities to methodologies. BioScience 53:491-502.

Holmgren, M., Scheffer, M., and Huston, M. A. 1997. The interplay of facilitation and competition in plant communities. Ecology 78:1966-1975.

Huston, M., and Smith, T. 1987. Plant succession: Life history and competition. The American Naturalist 130:168-198.

Jordan, W. R., Gilpin, M. E., and Aber, J. D. 1987. Restoration Ecology: A SyntheticApproach to Ecological Research. Cambridge: Cambridge University Press.

Keever, C. 1950. Causes of succession on old fields of the piedmont, North Carolina. Ecological Monographs 20:230-250.

Leopold, A. 1949. A Sand County Almanac. Oxford: Oxford University Press.

Leroy, E. C., Hobbs, R. J., O'Connor, M. H., and Pate, J. S. 1999. Agriculture as a mimic of natural systems. Agroforestry Systems 45(Special Issue):1-446.
Au: Pls. check the page range. 


\section{Lawrence R. Walker et al.}

Luken, J. O. 1990. Directing Ecological Succession. London: Chapman and Hall.

Marquez, V. J., and Allen, E. B. 1996. Ineffectiveness of two annual legumes as nurse plants for establishment of Artemisia californica in coastal sage scrub. Restoration Ecology 4:42-50.

McGlone, M. 1996. When history matters: Scale, time climate and tree diversity. Global Ecology and Biogeography Letters 5:309-314.

McIntosh, R. P. 1985. The Background of Ecology. Cambridge: Cambridge University Press.

McIntosh, R. P. 1999. The succession of succession: A lexical chronology. Bulletin of the Ecological Society of America 80:256-265.

McVicar, T. R., Rui, L., Walker, J., Fitzpatrick, R. W., and Changming, L. (eds.). 2002. Regional Water and Soil Assessment for Managing Sustainable Agriculture in China and Australia. Canberra: Australian Centre for International Agricultural Research.

Nordstrom, K. F., Lampe, R., and Vandemark, L. M. 2000. Reestablishing naturally functioning dunes on developed coasts. Environmental Management 25:37-51.

Odum, E. P. 1969. The strategy of ecosystem development. Science 164:262-270.

Palmer, M. A., Ambrose, R. F., and Poff, N. L. 1997. Ecological theory and community restoration ecology. Restoration Ecology 5:291-300.

Pandey, A. N., and Singh, J. S. 1985. Mechanism of ecosystem recovery: A case study from Kumaun Himalaya. Recreation and Revegetation Research 3:271-292.

Pärtel, M., Kalamees, R., Zobel, M., and Rosen, E. 1998. Restoration of species-rich limestone grassland communities from overgrown land: The importance of propagule availability. Ecological Engineering 10:275-286.

Pickett, S. T. A. 1989. Space-for-time substitutions as an alternative to long-term studies. In: Long-term Studies in Ecology. G. E. Likens (ed.). New York: Springer, pp. 110 135.

Pickett, S. T. A., Collins, S. L., and Armesto, J. J. 1987. A hierarchical consideration of causes and mechanisms of succession. Vegetatio 69:109-114.

Powell, E. A. 1992. Life history, reproductive biology, and conservation of the Mauna Kea silversword, Argyroxiphium sandwicense DC (Asteraceae), an endangered plant of Hawaii. Ph.D. Dissertation, University of Hawaii, Manoa.

Prach, K. 1994. Succession of woody species in derelict sites in central Europe. Ecological Engineering 3:49-56.

Ramensky, L. G. 1924. Basic regularities of vegetation covers and their study. (In Russian) Vestnik Opytnogo dêla Strende-Chernoz. Ob. Voronezh, 37-73.

Reinhart, K. O., Greene, E., and Callaway, R. M. 2005. Effects of Acer platanoides invasion on understory plant communities and tree regeneration in the northern Rocky Mountains. Ecography 28:573-582.

Robinson, G. R., and Handel, S. N. 2000. Directing spatial patterns of recruitment during an experimental urban woodland reclamation. Ecological Applications 10:174188.

Rui, L., Liu, G., Xie, Y., Qinke, Y., and Liang, Y. 2002. Ecosystem rehabilitation on the Loess Plateau. In: Regional Water and Soil Assessment for Managing Sustainable Agriculture in China and Australia. T. R. McVicar, L. Rui, J. Walker, R. W. Fitzpatrick, and L. Changming (eds.). Canberra: Australian Centre for International Agricultural Research, pp. 358-365.

Russell, J. S., and Isbell, R. F. (eds.). 1986. Australian Soils: The Human Impact. St. Lucia: University of Queensland Press.

Samuels, C. L., and Drake, J. A. 1997. Divergent perspectives on community convergence. Trends in Ecology and Evolution 12:427-432.

Sheley, R. L., and Krueger-Mangold, J. 2003. Principles for restoring invasive plantinfested rangeland. Weed Science 51:260-265.

Shiels, A. B., and Walker, L. R. 2003. Bird perches increase forest seeds on Puerto Rican landslides. Restoration Ecology 11:457-465. 
Shugart, H. H., and West, D.C. 1980. Forest succession modeling. BioScience 30:308313.

Sukopp, H. 2004. Human-caused impact on preserved vegetation. Landscape and Urban Planning 68:347-355.

Sukopp, H., and Starfinger, U. 1999. Disturbance in urban ecosystems. In: Ecosystems of Disturbed Ground. L. R. Walker (ed.). Amsterdam, The Netherlands: Elsevier, pp. 397-412.

Temperton, V. M., Hobbs, R. J., Nuttle, T., and Halle, S. (eds.). 2004. Assembly Rules and Restoration Ecology. Washington, D.C.: Island Press.

van Andel, J., and Aronson, J. (eds.). 2006. Restoration Ecology. Oxford, U.K.: Blackwell.

van Diggelen, R. 2006. Landscape: Spatial interactions. In: Restoration Ecology. J. van Andel and J. Aronson (ed.). Oxford, U.K.: Blackwell, pp. 31-44.

Wackernagel, M., and Rees, W. 1996. Our Ecological Footprint: Reducing Human Impact on the Earth. Gabriola Island: New Society.

Wali, M. K. (ed.). 1992. Ecosystem Rehabilitation. The Hague: SPB Academic Press.

Walker, J., and Reuter, D. J. 1996. Indicators of Catchment Health: A Technical Perspective. Collingwood: CSIRO Publishing.

Walker, J., Sharpe, P. J. H., Penridge, L. K., and Wu, H. 1989. Ecological field theory: The concept and field tests. Vegetatio 83:81-95.

Walker, J., Thompson, C. H., Fergus, I. F., and Tunstall, B. R. 1981. Plant succession and soil development in coastal sand dunes of subtropical eastern Australia. In: Forest Succession, Concepts and Application. D. C. West, H. H. Shugart, and D. B. Botkin (eds.). New York: Springer, pp. 107-131.

Walker, J., Thompson, C. H., Reddell, P., and Rapport, D. J. 2001. The importance of landscape age in influencing landscape health. Ecosystem Health 7:7-14.

Walker, L. R. 2005. Restoring soil and ecosystem processes. In: Forest Restoration in Landscapes: Beyond Planting Trees. S. Mansourian, D. Vallauri, and N. Dudley (eds.). New York: Springer, pp. 192-196.

Walker, L. R., and Chapin, F., S., III. 1987. Interactions among processes controlling successional change. Oikos 50:131-135.

Walker, L. R., and del Moral, R. 2003. Primary Succession and Ecosystem Rehabilitation. Cambridge: Cambridge University Press.

Walker, L. R., Clarkson, B. D., Silvester, W. B., and Clarkson, B. R. 2003. Colonization dynamics and facilitative impacts of a nitrogen-fixing shrub in primary succession. Journal of Vegetation Science 14:277-290.

Walker, L. R., Zarin, D. J., Fetcher, N., Myster, R. W., and Johnson, A. H. 1996. Ecosystem development and plant succession on landslides in the Caribbean. Biotropica 28:566-576.

Walker, T. W., and Syers, J. K. 1976. The fate of phosphorus during pedogenesis. Geoderma 15:1-19.

Wardle, D. A., Walker, L. R., and Bardgett, R. D. 2004. Ecosystem properties and forest decline in contrasting long-term chronosequences. Science 305:509-513.

Warming, E. 1895. Plantesamfund: Grunträk af den Ökologiska Plantegeografi. Copenhagen: Philipsen.

Weiher, E., and Keddy, P. (eds.). 1999. Ecological Assembly Rules: Perspectives, Ad vances, Retreats. Cambridge: Cambridge University Press.

Williams, B.G., Walker, J., and Tane, H. 2001. Drier landscapes and rising water tables: An ecohydrological paradox. Natural Resource Management 4:10-18.

Wilson, S. D. 1999. Plant interactions during secondary succession. In: Ecosystems of Disturbed Ground. L. R. Walker (ed.). Amsterdam, The Netherlands: Elsevier, pp. 611-632.

Young, T. P., Petersen, D. A., and Clary, J. J. 2005. The ecology of restoration: Historical links, emerging issues and unexplored realms. Ecology Letters 8:662-673.

Au: Pls. cite this reference in the text 
18 Lawrence R. Walker et al.

Zedler, J. B. 2005. Ecological restoration: Guidance from theory. San Francisco Estuary and Watershed Science 3(2):31 入

Zedler, J. B., and Callaway, J. C. 2003. Adaptive restoration: A strategic approach for integrating research into restoration projects. In: Managing for Healthy Ecosystems. D. J. Rappaport, W. L. Lasley, D. E. Rolston, N. O. Nielsen, C. O. Qualset, and A. B. Damania (eds.). Boca Raton: Lewis, pp. 167-174.

Zougmore, R., Zida, Z., and Kambou, N. F. 2003. Role of nutrient amendments in the success of half-moon soil and water conservation practice in semiarid Burkina Faso. Soil and Tillage Research 71:143-149. 